\title{
TENSILE PROPERTIES AND MIICROHARDNESS EVOLUTION IN MEDIUM CARBON SHEETS SUBJECTED TO CONTINUOUS SPD PROCESS
}

\author{
'Ondřej HILŠER, ${ }^{1}$ Stanislav RUSZ, ${ }^{1}$ Martin PASTRŇÁK, ${ }^{1}$ Rostislav ZABYSTRZAN \\ ${ }^{1}$ VSB - Technical University of Ostrava, Faculty of Mechanical Engineering, Department of Mechanical \\ Technology, Ostrava, Czech Republic, EU, \\ ondrej.hilser@vsb.cz, stanislav.rusz@vsb.cz, martin.pastrnak@vsb.cz, rostislav.zabystrzan@vsb.cz
}

https://doi.org/10.37904/metal.2020.3490

\begin{abstract}
Development of technologies to produce the very fine structure is currently very intensively accelerated. Even in scientific research, it is recognized that precisely controlled forming processes, including special processes, enabling control of technological parameters with regard to the structure refinement, and tied with the strengthening of materials, currently had the highest gradient of utilization efficiency of the scientific research findings in practice. Severe plastic deformation (SPD) processes have been extensively investigated in the last decade to facilitate the production processes on nano-structured or ultrafine-grained (UFG) materials with unique utility properties. This work deals with analysis of utilization the forming equipment that uses a method of metal forming - DRECE (Dual Rolling Equal Channel Extrusion), which was designed to produce a material with ultra-fine grain structure. Increasing the mechanical properties of the formed sheet metal strip is primary. It has demonstrated that the forming method leads to an increase of strength characteristics (Yield strength and Ultimate tensile strength) of the investigated medium carbon steel Ck55, while a slight decrease in plasticity of the formed steel. DRECE forming method has a positive effect on the microhardness distribution. With the increasing number of passes was observed that a HVO.1 difference between lower and upper sheet surface decreases to the minimum value, which depends on the processing of the initial state of the investigated sheet. The increasing dislocation density of cold severely deformed medium carbon steel resulted in an increase of the tensile properties and hardness.
\end{abstract}

Keywords: Severe plastic deformation, DRECE method, Medium carbon steel, Tensile properties, Hardness

\section{INTRODUCTION}

Severe plastic deformation (SPD) is a state of the art processing method for production of ultafine-grained (UFG) materials by imposing extreme levels of hydrostatic pressure and shear deformation on the material. Because UFG materials are superior to coarse-grained (CG) materials in terms of mechanical properties and physical characteristics [1]. The SPD process is capable of manufacturing bulk UFG materials and thus has great potential for fabrication of various industrial parts [2]. However, the basic SPD process: Equal Channel Angular Pressing (ECAP) [3], High Pressure Torsion Straining (HPT/HPTS) [4] and Accumulative Roll Bonding (ARB) [5] are limited for practical industrialization because it is hard to apply these discontinuous processes in mass-production.

In order to avoid such obstacles, continuous SPD processes have recently been invented using a variety of concepts by applying continuous drag force on a speciment [6]. Most of these are based on the ECAP process (e. g., Equal Channel Angular Rolling (ECAR) [7], Single Roll Angular Rolling (SRAR) [8] and most popular ECAP-Conform [9]). Because these continuous processes require a large amount of drag force to drive the speciment through the deformation zone (channel angular region) where two channels are intersected at a certain angle. 
However, these continuous SPD processes share a common disadvantage in terms of deformation homogeneity. They are accompanied by deformation behavior similar to that of the conventional ECAP process [10]. In ECAP, the flow velocities between the lower and upper parts of the specimen inevitably differ, which results in a deformation gradient in the cross section. This is particularly true of the formation of a less deformed region near the lower surface of a specimen [11]. Such heterogenous deformation can degrade the material stability associated with mechanical properties and microstructures, which is particularly lethal for metal sheets with a small thickness to widths ratio [12].

In this paper, we propose a continuous SPD process named „Dual Rolls Equal Channel Extrusion (DRECE)“ to induce highly uniform SPD throughout metal sheets by engaging circumferential shear deformation in the channel angular deformation process. Because the thickness of the metal sheets is restored to the initial thickness after DRECE process, the microstructure and mechanical properties of same thickness specimens were investigated by varying the number of repetitive passes.

\subsection{Dual Rolls Equal Channel Extrusion}

The DRECE method is based on the ECAP-Conform methods combination. The material is introduced into the working space and then extruded through the feed roller by means of pressure rollers through the shaping tool without changing cross-section of the extruded sheet. Severe plastic deformation carried out this way influence the change of the structure and mechanical properties in relation to the initial state of investigated material.

Figure 1 presents the schematic illustration of DRECE process.

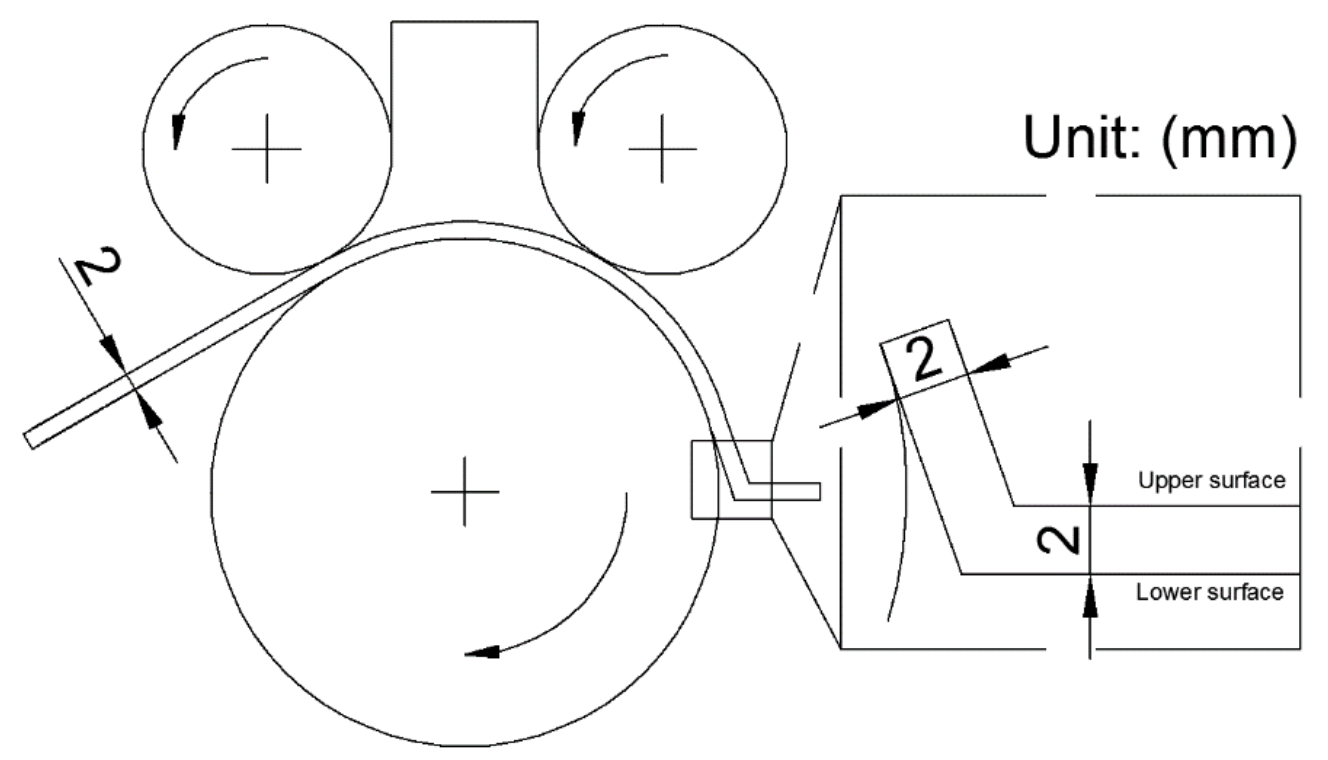

Figure 1 Schematic illustration of DRECE process principle

The DRECE method is a modification/combination of two commonly known SPD techniques: the DCAP method (dissimilar channel angular pressing) and ECAP-CONFORM (continuous equal channel angular pressing), and it has been developed for forming metal sheets with maximum dimensions of $58 \times 2 \times 1000 \mathrm{~mm}$. In this technique, the sample is inserted into the working space and then extruded through the rollers without changing their dimension. When comparing the DRECE method to the other commonly known SPD techniques, we must remember that the strain accumulation after a single pass is not as high as i.e., in the ECAP process. Similar to the ECAP process, the repetitive deformations increase the accumulated strain, which affects the microstructure and thus changes the mechanical properties. The main advantage of the DRECE method is the length of the work specimen and the form of the batch material sheet. Such form of the batch material is typical (for automotive industry applications). 


\section{INVESTIGATION PROCEDURES}

\subsection{Material}

The study material was a cold-rolled metal sheets of a medium-carbon steel Ck55. The chemical composition of the tested steel is shown in Table 1.

Table 1 Chemical composition of investigated steel Ck55

\begin{tabular}{|c|c|c|c|c|c|c|c|}
\hline Element & $\mathbf{C}$ & Mn & Si & P & S & Cr & Fe \\
\hline wt. \% & 0.55 & 0.72 & 0.20 & 0.02 & 0.01 & 0.10 & rest. \\
\hline
\end{tabular}

\subsection{Investigation methods}

The strip sheets of Ck55 with dimensions $58 \times 2 \times 2000 \mathrm{~mm}$ were subjected to max. 6 passes by continuous severe plastic deformation method DRECE. Before the DRECE process, the upper surface of the investigated steel in the contact with the forming tool was coated with Gleit - $\mu$ HP 515 lubricant to minimize friction. The pressure on the feed roller was 150 bar, while on the pressure rollers (before the deformation zone) 30 bar. The rotation speed of the roll was approximately $3 \mathrm{rpm}$. The processes were repeated in up to six passes without rotation of the sheets between each pass (deformation route type $A$ ).

Mechanical properties evaluation of the analyzed steel after individual DRECE passes were determinate by using test-stand LVF 100-HM according to the ISO 6892-1.

The Vickrers hardness was measured under a load $100 \mathrm{~g}$ (HV0.1) and a with a dwell time of $10 \mathrm{~s}$. The HV0.1 was measured across sheet thickness from lower to upper surface.

\section{INVESTIGATION RESULTS}

\subsection{Tensile properties}

In the tensile stress-strain curves (Figure 2), both the yield strength $\left(\mathrm{Rp}_{0.2}\right)$ and ultimate tensile strength ( $\left.\mathrm{Rm}\right)$ are significantly intensified with increasing number of passes, especially after the first pass. After a low number of passes, strengthening mainly by strain hardening becomes prominent and grain boundary strengthening by grain refinement is also exhibited with increasing number of passes. Total elongation to failure $(A)$ showed the opposite trend, representing the strength-ductility trade off, but there was no significant drop in the ductility from the fourth pass to sixth pass results.

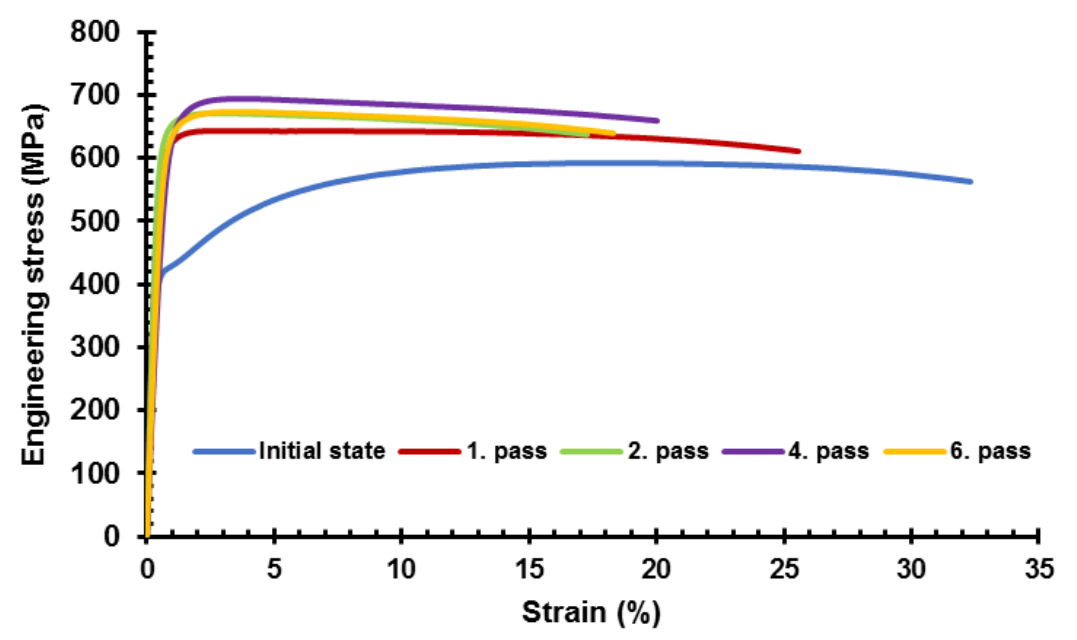

Figure 2 Stress-Strain tensile curves of investigated steel 
After the first DRECE pass, the yield stress $\left(\mathrm{Rp}_{0.2}\right)$ increased from initial $378 \mathrm{MPa}$ to $588 \mathrm{MPa}$ and Ultimate tensile strength $(\mathrm{Rm})$ increased from initial $554 \mathrm{MPa}$ to $642 \mathrm{MPa}$. Presented results show that strength is increased only slightly. After the second pass, the values of of $\mathrm{Rp}_{0.2} 629 \mathrm{MPa}$ and $\mathrm{Rm} 672 \mathrm{MPa}$ were achieved. The results of tensile strength after the sixth pass decreased to $627 \mathrm{MPa}\left(\mathrm{Rp}_{0.2)}\right)$ and value of $\mathrm{Rm}$ increased to $672 \mathrm{MPa}$. Due to increasing of dislocation density during severe plastic deformation at room temperature, the plasticity of investigated steel decreases. The elongation to failure $(A)$ decreased from initial $33 \%$ to $18.3 \%$ (after the sixth DRECE pass).

\subsection{Microhardness distribution}

Figure 3 shows HV0.1 evolution in thickness, depending to DRECE passes. Above all, the remarkable point in the hardness results is that the region in the vicinity of the lower surface, where the conventional ECAP process imposes significantly less deformation, becomes hardened to a degree similar to that in the upper surface region. Therefore, the hardness distribution in the DRECE-processed sheet is more homogeneous than in the conventional ECAP-processed bar, which is a distinctive feature of the DRECE process.

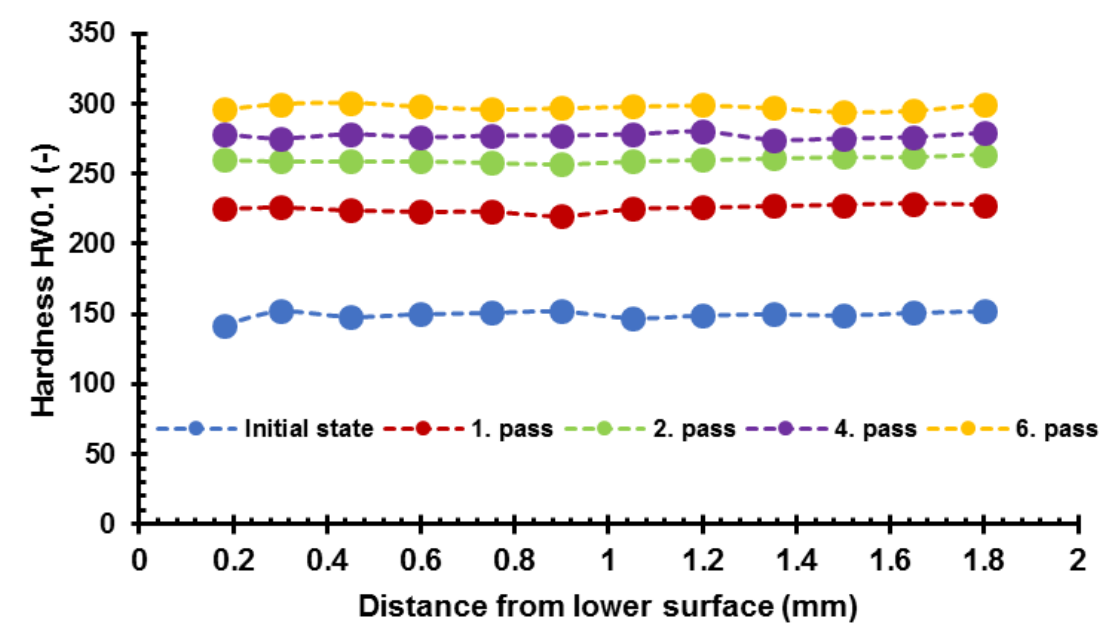

Figure 3 Vickers HV0.1 microhardness distribution from the lower to upper surface of the initial state and DRECE-processed sheets

\section{CONCLUSION}

In conclusion it may be stated that the forming device that is uses for a new method of metal forming DRECE (Dual Rolling Equal Channel Extrusion) meets the requirements for achievement of higher mechanical properties of $\mathrm{Ck} 55$ sheets without changing the dimensions of the formed sheet metal strip (cross-section) and extruded wire in accordance with the default theoretical prediction.

The results gained from the investigation are used to verify strain states in developing a DRECE technology. The obtained results show that the two passes of the sheet by the processing tool is the optimum number of passes to increase the mechanical properties of all verified materials. Furthermore, these mechanical properties decrease, which is caused by depletion of the stock of material plasticity. The parameters of the ultimate strength and the yield value rise at the expense of elongation, which is undesirable due to application in industry. In further research work it is necessary to propose a suitable type of heat treatment in terms of maintaining prestraining of the material and a slight decrease in ductility.

From the physico-metallurgical point of view has been demonstrated real possibility of applying new technologies (resp. forming methods) for refining the material structure and thus an increase of mechanical properties of metallic materials. Further developments could point to adjust the forming equipment for the 
possibility of integration into production lines. Future commercial outputs are semi-finished products of higher quality with high strength and reduced weight, replacing the currently used materials.

\section{ACKNOWLEDGEMENTS}

This article was financed by project TH04010416: "Development of a new technology for increasing the quality of steel strips" and by project SP2020/106, entitled: "Research and Development of Modern Technologies of Welding, Forming and Surface Treatment Including Production Process Control".

\section{REFERENCES}

[1] VALIEV, R. Z., ISLAMGALIEV, R. K., ALEXANDROV, I. V. Bulk nanostructured materials from severe plastic deformation. Progress in Materials Science. 2000, vol. 45, pp. 103-189.

[2] VALIEV, R. Z. Recent developments of severe plastic deformation techniques for processing bulk nanostructured materials. Materials Science Forum. 2008, vol. 579, pp. 1-14.

[3] TAŃSKI, T., SNOPIŃSKI, P., PAKIEŁA, W., BOREK, W., PRUSIK, K., RUSZ, S. Structure and properties of AIMg after combination of ECAP and post-ECAP ageing. Archives of civil and mechanical engineering. 2016, vol. 16, no. 3, pp. 325-334.

[4] ZHILYAEV, A. P., LANGDON, T. G. Using high-pressure torsion for metal processing: Fundamentals and applications. Progress in Materials Science. 2009, vol. 53, no. 6, pp. 893-979.

[5] TROJANOVÁ, Z., DŽUGAN, J., HALMEŠOVÁ, K., NÉMETH, G., MINÁRIK, P., LUKÁČ, P., BOHLEN, J. Influence of accumulative roll bonding on the texture and tensile properties of an AZ31 magnesium alloy sheets. Materials. 2018, vol. 11, no. 1, pp. 1-14.

[6] ČADA, R. Evaluation of strain and material flow in sheet-metal forming. Journal of Materials Processing Technology. 2003, vol. 138, no. 1-3, pp. 170-175.

[7] KVAČKAJ, T., KOVÁČOVÁ, A., KOČIŠKO, R., BIDULSKÁ, J., LITYŃSKA-DOBRZAŃSKA, L., JENEI, P., GUBICZA, J. Microstructure evolution and mechanical performance of copper processed by equal channel angular rolling. Materials Characterization. 2017, vol. 134, pp. 246-252.

[8] LEE, H. H., YOON, J, I., KIM, H. S. Single-roll angular-rolling: A new continuous severe plastic deformation process for metal sheets. Scripta Materialia. 2018, vol. 146, pp. 204-207.

[9] PALÁN, J., MALEČEK, L., HODEK, J., ZEMKO, M., DŽUGAN, J. Possibilities of biocompatible materil producton using conform SPD technology. Archives of Materials Science and Engineering. 2017, vol. 88, no. 1, pp. 5-11.

[10] VINOGRADOV, A., ESTRIN, Y. Analytical and numerical approaches to modelling severe plastic deformation. Progress in Materials Science. 2018, vol. 95, pp. 172-242.

[11] KOWALCZYK, K., JABLOŃSKA, M., RUSZ, S., BEDNARCZYK, I. Influence of the DRECE process of severe plastic deformation on the mechanical properties of the ultra-low carbon interstitial free steel. Archives of Metallurgy and Materials. 2018. vol. 63, no. 4, pp. 2095-2100.

[12] CIEMIOREK, M., ORŁOWSKA, M., LEWANDOWSKA, M. Ultrafine-grained plates and sheets: Processing, Anisotropy and Formability. Advanced Engineering Materials. 2020, vol. 22, no. 1, pp. 1-12. 